\title{
OPEN Phytotoxic effects of invasive Ageratina adenophora on two native subtropical shrubs in Nepal
}

\author{
Tej Bahadur Darji ${ }^{1}$, Barsha Adhikari ${ }^{2}$, Seeta Pathak ${ }^{1}$, Shristi Neupane ${ }^{2}$, Lal B. Thapa ${ }^{1 凶}$, \\ Tara Datt Bhatt' ${ }^{3}$, Ramesh Raj Pant ${ }^{2}$, Gunanand Pant ${ }^{4}$, Khadka Bahadur Pal ${ }^{5}$ \& \\ Kiran Bishwakarma ${ }^{6}$
}

The response of native plants to allelopathic interference of invasive species may differ from species to species. In this study, the phytotoxic effects of Ageratina adenophora were tested on two native shrubs (Osbeckia stellata and Elsholtzia blanda) of Nepal. Both the shrubs were grown in pots under treatments of $A$. adenophora fresh leaves and root leachates, and litter. Then, the seedling length and biomass were compared among the treatments. The results show that $A$. adenophora litter has stimulatory effects but the leachates from fresh leaves and root are phytotoxic to the growth and development of native shrubs. Infrared Spectroscopy (IR) analysis confirmed the presence of O-H (Hydroxyl), N-H (Amines), C $\equiv \mathrm{C}$ (Alkynes), and C-H stretching (Aromatic) or C-O-C stretching (Ethers) in the leachates representing harmful allelochemicals. The invaded soil by $A$. adenophora had low $\mathrm{pH}$ and a high amount of organic matter, total nitrogen, phosphorus, and potassium than the uninvaded soil. The results indicate that the native $O$. stellata and $E$. blanda are harmed by $A$. adenophora in nature by leaching of allelochemicals and probably by reducing the soil $\mathrm{pH}$. Overall, this study has provided valuable insights regarding the effects of $A$. adenophora invasion on native shrubs and revealing the potential mechanism of its invasiveness.

Ageratina adenophora (Spreng.) R.M. King \& H. Rob., a perennial shrub of family Asteraceae, is commonly called the Crofton weed. It is the native weed in Mexico $^{1}$. It has become highly invasive and rapidly spread worldwide including Asia, Australia, and Africa ${ }^{1-3}$. In the invaded regions, it has threatened the biodiversity of native forests, rangelands, and farmlands ${ }^{4}$. This weed has the capability to regenerate by vegetative methods and also reproduce from its minute seeds which are produced in huge numbers. It proliferates rapidly in the invaded sites and forms its monoculture ${ }^{5,6}$.

Ageratina adenophora has been naturalized in Nepal where it was first reported in $1952^{7}$. In Nepal, it is locally called 'Kalo Banmara' meaning the 'Forest Killer Plant' having dark green leaves. It has been spreading throughout the country from tropical regions to northern border crossing through the subtropical mountain region $^{7}$. It has been spread along the trails, roads, disturbed sites, and margins or open canopy areas of the forests of $\mathrm{Nepal}^{8-14}$.

This plant is known to have negative impacts on native vegetation ${ }^{15-17}$. It affects plant community composition, species diversity, and abundance ${ }^{15}$. Thapa et al. (2020) reported that the plant is responsible to reduce the native species richness in the invaded sites in Nepal ${ }^{17}$. Allelopathy has been one of the mechanisms affecting other plants by A. adenophora ${ }^{18}$. Negative impacts on physiology and morphology of some crops (e.g., rice), weeds (e.g., Lolium perenne, Trifolium repens, Galinsoga parviflora, and Medicago sativa) and native trees (e.g., Schima wallichii and Alnus nepalensis) by aerial parts (leaves and litter) and roots of this species have been reported previously ${ }^{16,19-22}$. Negative effects on native seed germination and growth by volatile compounds from the litter of $A$. adenophora have also been reported ${ }^{17,23}$. In the inhibition, there is role of several allelochemicals present in the aerial and underground parts of this plant ${ }^{23-25}$. The allelochemicals are the secondary metabolites that can

${ }^{1}$ Central Department of Botany, Institute of Science and Technology, Tribhuvan University, Kathmandu, Nepal. ${ }^{2}$ Central Department of Environmental Science, Institute of Science and Technology, Tribhuvan University, Kathmandu, Nepal. ${ }^{3}$ Department of Plant Resources, Ministry of Forests and Environment, Government of Nepal, Thapathali, Kathmandu, Nepal. 'Department of Biology, Kailali Multiple Campus, Tribhuvan University, Dhangadhi, Nepal. ${ }^{5}$ Department of Chemistry, Tri-Chandra Multiple Campus, Tribhuvan University, Kathmandu, Nepal. ${ }^{6}$ Institute of Tibetan Plateau Research, Chinese Academy of Sciences, Beijing, China. ${ }^{\square}$ email: lal.thapa@ cdbtu.edu.np 
(a)

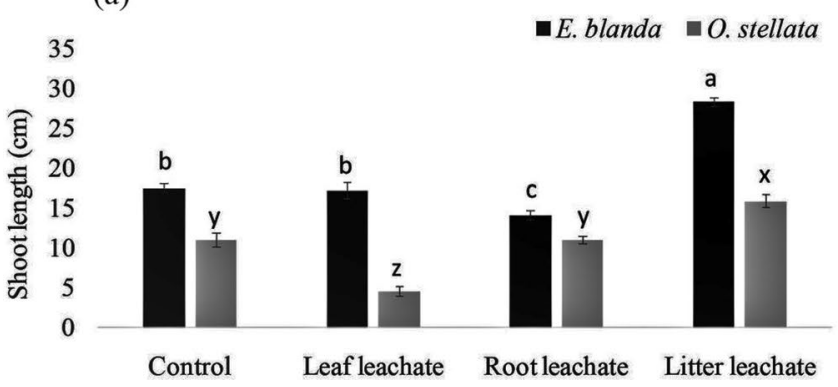

(b)

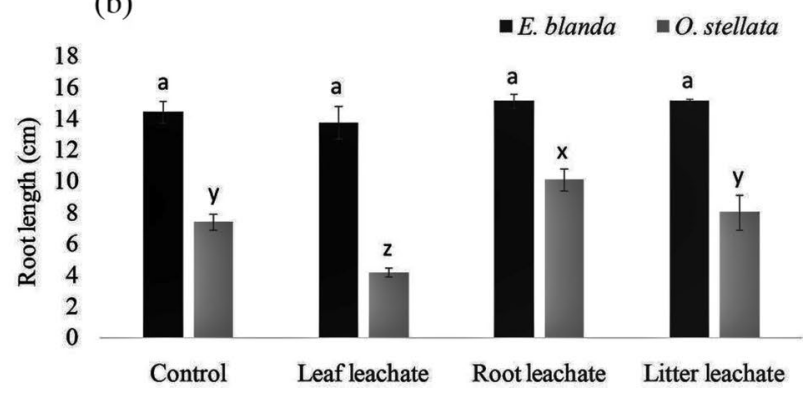

Figure 1. Effect of A. adenophora leachates on (a) shoot length and, (b) root length of native E. blanda and $O$. stellata. Different letters above the error bar indicate significant differences among the treatments ('a', 'b', and 'c' for E. blanda; 'x', 'y', and ' $\mathrm{z}$ ' for O. stellata; $p<0.05$ ).

be classified according to their carbon skeletal structure and type of functional groups such as alcohols, amines, carboxylic acids ${ }^{26}$. Thus, the functional group analysis is one of the most satisfactory and applicable methods of determining organic compounds which also lends towards the identification of organic compounds ${ }^{27}$. Such analyses have significance in understanding the chemical nature of invasive weed's allelochemicals.

Although the previous studies have documented the negative impacts of $A$. adenophora on the native species, the insights regarding whether $A$. adenophora affects all the native plants always negatively or it may also have positive impacts on some native species are very scarce. For this, several experiments can be performed by testing the effect of $A$. adenophora on the native plants from invaded sites. We hypothesized that the native plants' response to allelopathic interference of $A$. adenophora differs from species to species. Some native species are found frequently associated with $A$. adenophora in the invaded sites. There might be two reasons for such an association: one, the invasive species might have started colonization in the native region and the native species might be at the stage of replacement/inhibition by the invasive species. Another, the native species might have resisted the negative effects of invasion and therefore, the association has no significant negative relationship or sometimes there might be a positive interaction between them. Such phenomena cannot be predicted easily by simple field observations.

Two of the native species (Osbeckia stellata and Elsholtzia blanda) in the mid-hill region of central Nepal are frequently associated with $A$. adenophora invaded forests. Both of these species are the most common subtropical native shrubs in Nepal. As discussed above, it cannot be expected that these two native species are either tolerating the negative effects of $A$. adenphora or they are harming by the invasion. In such a condition, proper experiments should be designed to know the actual interactions among them. In this study, growth response of above mentioned native shrubs were tested against $A$. adenphora fresh leaves and roots leachates, and the litter. In addition, the chemical groups present in the leachates and the potential impact of $A$. adenophora invasion in soil was also explored. Testing phytotoxicity of $A$. adenophora on native shrubs of Nepal is a novel work. It would have significance to know the parts and chemicals found in A. adenphora contributing positively or negatively to the growth and development of native shrub species and soil properties.

\section{Results}

Shoot and root length. Shoots of both the native species E. blanda and O. stellata were longer in A. adenophora litter treatment compared to the control plants. A. adenophora root leachate reduced the shoot length of $E$. blanda while the leaf leachate did not show inhibitory or stimulatory effects. Interestingly, the shoot length of $O$. stellata was inhibited by the fresh leaf leachate, not by the root leachate of $A$. adenophora (Fig. 1a, $\mathrm{df}=3$, $p<0.001)$.

In the case of root length, there was no stimulatory or inhibitory effects on $E$. blanda by all the treatments (Fig. $1 \mathrm{~b}, \mathrm{df}=3, p=0.44$ ). The roots of $O$. stellata were longer in the treatment of $A$. adenophora root leachate comparing to the control plants while the leaf leachate showed inhibition to the root length (Fig. $1 \mathrm{~b}, \mathrm{df}=3, p<0.001$ ).

Shoot and root dry weight (biomass). Similar to the shoot length, A. adenophora litter increased dry weight of shoots in both native species. Comparing to the control plants shoots were lighter in the treatments of A. adenophora leaf and root leachates. The root leachate did not inhibit the dry weight of $O$. stellata but the leaf leachate reduced the weight significantly (Fig. $2 \mathrm{a}, \mathrm{df}=3, p<0.001$ ).

The dry weight of roots in both the native species was increased by A. adenophora litter. There was no significant effects of both the leaf and root leachate on the root dry weight of E. blanda. The root leachate also increased dry weight of roots in O. stellata while the leaf leachate reduced the dry weight (Fig. $2 \mathrm{~b}, \mathrm{df}=3, p<0.001$ ).

Chlorophyll a and b. Ageratina adenophora litter did not increase or decrease the content of chlorophyll - a and $\mathrm{b}$ in both E. blanda and O. stellata but the leaf and root leachates inhibited chlorophyll content significantly [Fig. 3, $\mathrm{df}=3, p<0.01$ (E. blanda) and $p<0.001$ (O. stellata)].

Infrared spectroscopy (IR) analysis. Infrared spectroscopy (IR) analysis showed that all the leachates (leaf, litter, and root) of $A$. adenophora have similar functional groups, that were $\mathrm{O}-\mathrm{H}$ (Hydroxyl), $\mathrm{N}-\mathrm{H}$ (Amine), 
(a)

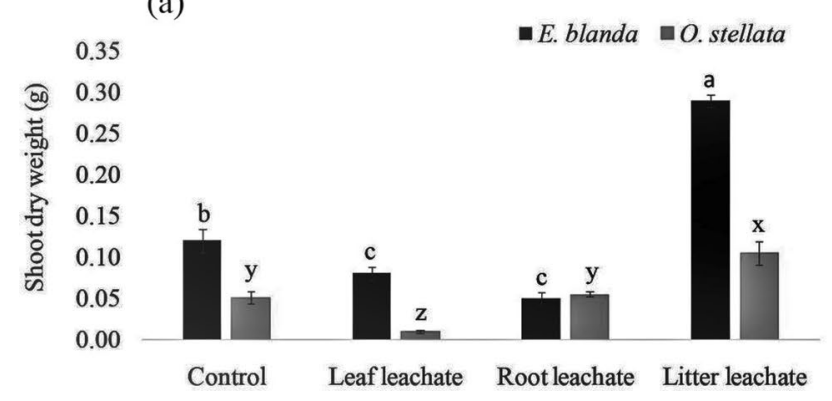

(b)

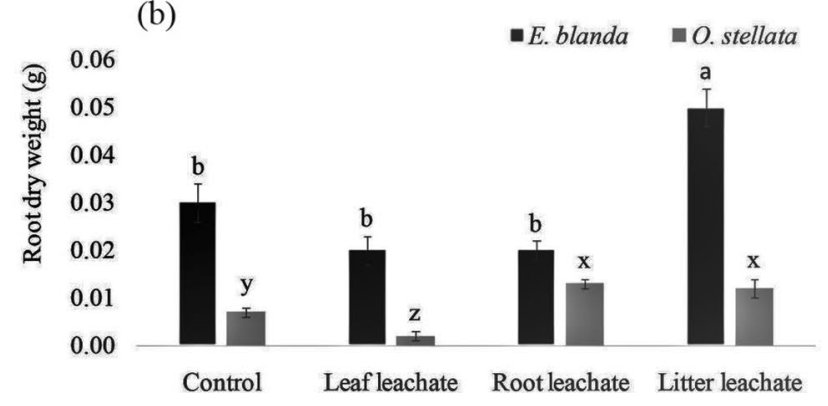

Figure 2. Effect of A. adenophora leachates on (a) shoot dry weight and (b) root dry weight of native E. blanda and $O$. stellata. Different letters above the error bar indicate significant differences among the treatments ('a', 'b', and 'c' for E. blanda; ' $\mathrm{x}$ ', ' $\mathrm{y}$ ', and ' $\mathrm{z}$ ' for O. stellata; $p<0.05$ ).

(a)

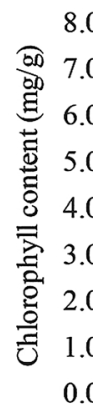

-E. blanda $\quad$ O. stellata

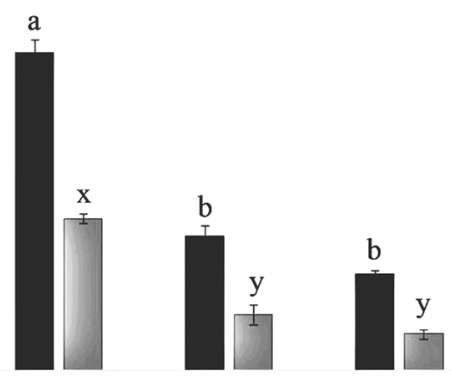

Litter

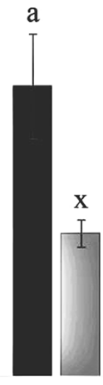

Control (b)

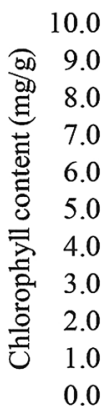

0.0

Control
E. blanda O. Stellata

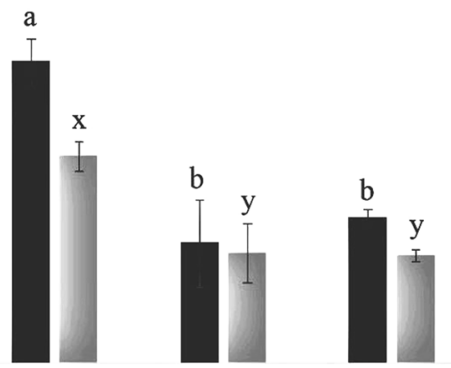

Litter

Leaf leachate Root leachate

Figure 3. Effect of A. adenophora leachates on (a) chlorophyll - a and, (b) chlorophyll - b of native E. blanda and $O$. stellata. Different letters above the error bar indicate significant differences among the treatments ('a', 'b', and 'c' for E. blanda; and 'x', 'y', and ' $z$ ' for O. stellata; $p<0.05$ ).

$\mathrm{C} \equiv \mathrm{C}$ (Alkynes), $\mathrm{C}-\mathrm{H}$ stretching (Aromatic) or $\mathrm{C}-\mathrm{O}-\mathrm{C}$ stretching (Ethers) groups (Fig. 4, Table 1). The wavenumber of the hydroxyl group was $3255.84 \mathrm{~cm}^{-1}$, alkynes had wavenumbers ranged from $2113.98 \mathrm{~cm}^{-1}$ to $2129.41 \mathrm{~cm}^{-1}$, amines had $1635.64 \mathrm{~cm}^{-1}$, and the wavenumber of $\mathrm{C}-\mathrm{H}$ stretching (Aromatic) or C-O-C stretching (Ethers) varied from $995.27 \mathrm{~cm}^{-1}$ to $1018.41 \mathrm{~cm}^{-1}$ (Fig. 4, Table 1).

Soil analysis. Soil analysis showed differences in $\mathrm{pH}$, soil organic matter (OM), total nitrogen (N), available phosphorus $(\mathrm{P})$ and potassium $(\mathrm{K})$ between $A$. adenophora invaded and uninvaded sites. A. adenophora invaded soil had low $\mathrm{pH}(5.13 \pm 0.06)$ than the uninvaded soil $(5.61 \pm 0.10)$. The concentrations of organic matter $(\mathrm{OM})$, total nitrogen, available phosphorus and potassium were significantly high in the invaded soil comparing to the uninvaded soil (Table 2).

\section{Discussion}

Ageratina adenophora litter showed positive effects on E. blanda seedling growth. Both the shoots and roots of native E. blanda were longer in A. adenophora litter treated plants compared to the control plants (Fig. 1). A similar effect was found in shoot and root biomass as well (Fig. 2). It confirms that A. adenophora may also have a supportive role in the growth and development of native E. blanda. On the other hand, shoot length and biomass were reduced by $A$. adenophora root leachate (Figs. 1,2) but leaf leachate reduced only the biomass. From this result, it can be stated that E. blanda taking benefit from A. adenophora litter can be harmed in another way by roots or fresh leaves of A. adenophora. Overall, the impacts of A. adenophora to E. blanda could be negative because one component (litter) facilitates the growth whereas two-components (root and fresh leaves) have an inhibitory role. Simultaneously, the toxic effect of root and leaf leachates on chlorophyll contents (Fig. 3) may impair the light energy uptake during photosynthesis in E. blanda.

In the case of native O. stellata, the litter of A. adenophora increased shoot length but decreased the root length. The root leachate increased root length and biomass but decreased shoot length and biomass (Figs. 1, 2). This effect may create an abnormality in the root-shoot ratio as there is a stimulatory effect on one part (aerial or underground) and an inhibitory effect on another part (aerial or underground). The root-shoot ratio indicates overall health of plants ${ }^{28,29}$. Any change in normal root-shoot ratio plants would be an indication of a change in the overall health of plants ${ }^{30}$. The effect of the root and leaf leachates on chlorophylls of $O$. stellata was similar to the E. blanda. These results have confirmed that the invasive A. adenophora is capable to alter the root-shoot ratio and content of the photosynthetic pigments of native O. stellata. 

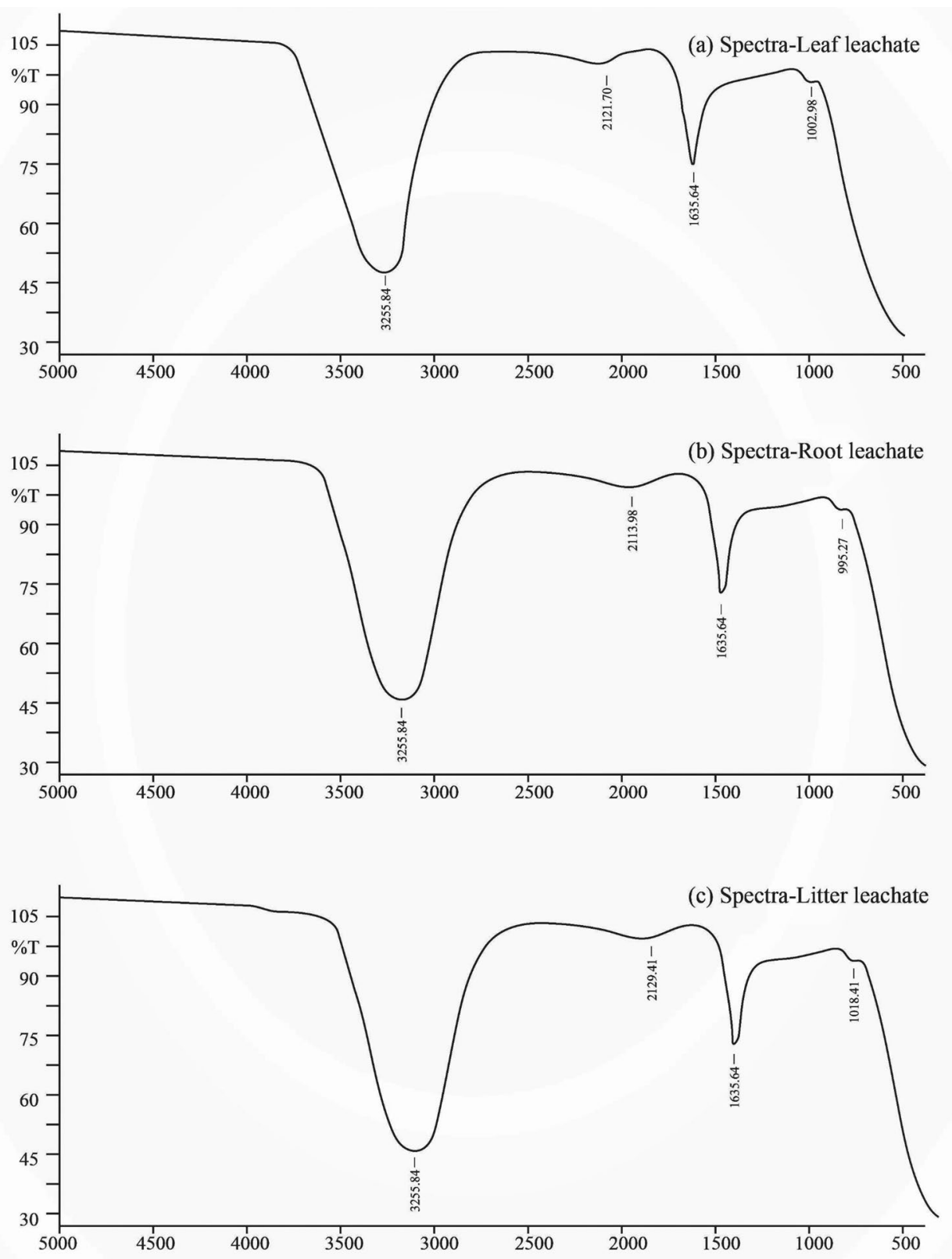

Figure 4. Spectra of IR analysis in A. adenophora fresh leaf, root and litter leachates. The names of the functional groups are given in Table 1.

\begin{tabular}{|l|l|l|l|l|}
\hline \multirow{4}{*}{ S.N. } & \multicolumn{2}{|l|}{ FTIR peak value } & \multicolumn{1}{|l|}{} \\
\cline { 2 - 4 } & Leaf leachate & Root leachate & Litter leachate & Functional groups \\
\hline 1 & 3255.84 & 3255.84 & 3255.84 & Hydroxyl $(\mathrm{O}-\mathrm{H})$ \\
\hline 2 & 2121.7 & 2129.41 & 2113.98 & Alkynes $(\mathrm{C} \equiv \mathrm{C})$ \\
\hline 3 & 1635.64 & 1635.64 & 1635.64 & Amines $(\mathrm{N}-\mathrm{H})$ \\
\hline 4 & 1002.98 & 1018.41 & 995.27 & C-H stretching (Aromatic) or C-O-C stretching (Ethers) \\
\hline
\end{tabular}

Table 1. Functional groups of chemicals found in A. adenophora leachates. 


\begin{tabular}{|c|c|c|c|c|c|}
\hline Soil parameters & Invaded soil & Uninvaded soil & df & t-value & $p$ value \\
\hline $\mathrm{pH}$ & $05.13 \pm 0.06 \mathrm{~b}$ & $05.61 \pm 0.10 \mathrm{a}$ & \multirow{4}{*}{18} & -4.04 & 0.001 \\
\hline $\mathrm{OM}(\%)$ & $05.08 \pm 0.15 \mathrm{a}$ & $04.25 \pm 0.15 \mathrm{~b}$ & & 3.809 & 0.001 \\
\hline Total N (\%) & $00.29 \pm 0.01 \mathrm{a}$ & $00.23 \pm 0.01 \mathrm{~b}$ & & 7.163 & $<0.001$ \\
\hline $\mathrm{K}(\mathrm{kg} / \mathrm{ha})$ & $83.92 \pm 3.79 \mathrm{a}$ & $73.07 \pm 3.63 \mathrm{~b}$ & & 2.064 & 0.050 \\
\hline Soil parameters & Invaded soil & Uninvaded soil & df & Mann-Whitney U & $p$ value \\
\hline $\mathrm{P}(\mathrm{kg} / \mathrm{ha})$ & $00.44 \pm 0.06 \mathrm{a}$ & $00.33 \pm 0.10 \mathrm{~b}$ & 18 & 20 & 0.023 \\
\hline
\end{tabular}

Table 2. Data on soil analysis (A. adenophora invaded and uninvaded soils). The letters ' $a$ ' and ' $b$ ' after the mean value \pm SE indicate significant differences $(p<0.05)$.

There are not many validations showing the effects of $A$. adenophora on native herbs, shrubs, and tree species. Most commonly the researchers consider the crop plants and weeds as the test species. The results of some of the previous studies are in support of the findings of our study. For example, Das et al. (2018) tested the effect of this weed on seed germination and seedling growth of some crop plants and weeds ${ }^{31}$. The crop plants were Triticum aestivum and Brassica campestris and the weeds were Ageratum conyzoides, Bidens pilosa, Galinsoga parviflora and Cyperus rotundus. They have found that the extracts of $A$. adenophora inhibited the seed germination and seedling length of the tested plants. Similarly, Thapa et al. (2020) found that the growth and development of seedlings of native trees (Schima wallichii and Alnus nepalensis) were inhibited by A. adenophora fresh leaves and leaf extract ${ }^{16}$. Regarding the allelopathic mechanism of inhibition to native plants by invasive plants, the plant parts which are potential to produce harmful allelochemicals should be identified. Our study reveals that the fresh leaves and roots of $A$. adenophora are the parts which are the potential to produce harmful allelochemicals that can inhibit native species growth and development.

Diverse chemical compounds such as monoterpenes, sesquiterpenes, diterpenes and triterpenes, phenylpropanoids, flavonoids, coumarins, sterols, and alkaloids have been reported from A. adenophora. As examples, Zhou et al. (2013) have identified eleven phenolic compounds such as 7-hydroxy-8,9-dehydrothymol 9-O-transferulate; 7-hydroxythymol 9-O-trans-ferulate; 7,8-dihydroxythymol 9-O-trans-ferulate; 7,8-dihydroxythymol 9-O-cis-ferulate; methyl (7R)-3-deoxy-4,5-epoxy-D-manno-2-octulosonate 8-O-trans-p-coumarate; methyl (7R)-3-deoxy-4,5-epoxy-D-manno-2-octulosonate 8-O-cis-p-coumarate; and o-coumaric acid, etc. having inhibitory effects on Arabidopsis seed germination ${ }^{32}$.

Quinic acid derivative (5-O-trans-o-coumaroylquinic acid methyl ester; chlorogenic acid methyl ester; macranthoin F and macranthoin G were isolated by Zhang et al. (2013) from the aerial parts of A. adenophora ${ }^{33}$. Similarly, thymol derivatives such as 7,9-diisobutyryloxy-8-ethoxythymol; 7-acetoxy-8-methoxy-9-isobutyry-

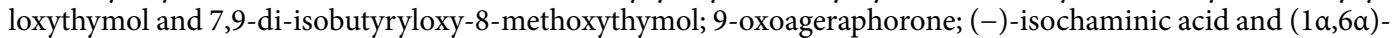
10-hydroxycar-3-ene-2-one were identified by Dong et al. (2017) from roots of A. adenophora ${ }^{34}$. Including these chemical compounds and other monoterpenes from the aerial parts of A. adenophora are reported to have allelopathic potential ${ }^{33,35}$.

For the identification of at least the functional groups in chemicals found in the leachates of $A$. adenophora, Infrared Spectroscopy (IR) analysis was carried out in this study. The IR analysis is the most common and widely used spectroscopic technique for determining functional groups of chemical compounds existing in the leachates. The analyses had confirmed four functional groups in the leachates. The wavenumbers $3255.84 \mathrm{~cm}^{-1}$ and $1635.64 \mathrm{~cm}^{-1}$ indicated the presence of $\mathrm{O}-\mathrm{H}$ (Hydroxyl) group and $\mathrm{N}-\mathrm{H}$ (Amine) group, respectively in all types of $A$. adenophora leachates (root, fresh leaves, and litter) (Table 1). The wavenumbers ranged from 2113.98 to $2129.41 \mathrm{~cm}^{-1}$ found in the leachates indicated alkynes. Similarly, the wavenumbers ranged from 995.27 to $1018.41 \mathrm{~cm}^{-1}$ indicates the presence of $\mathrm{C}-\mathrm{H}$ stretching (Aromatic) or C-O-C stretching (Ethers) in the leachates (Table 1).

Existence of these functional groups confirms that the allelochemicals identified by previous researchers are present in the root, leaf, and litter leachates and they are almost similar based on the functional groups. But, the treatments of the root leachate, fresh leaf leachate, and litter have shown different effects on the tested native species i.e., one can inhibit only aerial parts (shoot) or belowground part (root) and another can inhibit both shoot and root of native species (Figs. 1,2). Hence, it can be expected that the concentrations of allelochemicals may vary in different parts of $A$. adenophora and the effects on growth and development of native species may depend on the concentrations. Also, further analysis of chemical compounds and their allelopathic effects should be explored to understand the exact effect on particular native species.

The study on allelopathic inhibition of the invasive species on the selected native species markedly shows that aerial and belowground parts (leaves and roots) are phytotoxic to the native plants. Fresh leaves, litter, and root extracts of $A$. adenophora were found to be toxic to the growth and development of native trees such as Schima wallichii and Alnus nepalensis in Nepal ${ }^{16,19}$. Phenologically, A. adenophora produces new leaves starting from pre-monsoon and its luxuriant growth is seen in the monsoon ${ }^{16}$. Meanwhile, the native species E. blanda and $O$. stellata also germinate during pre-monsoon to early monsoon. This coincidence has a high probability of facing allelopathic effect by the native seedlings because the rainwater washes the allelochemicals from aerial parts of $A$. adenophora and mix into the soil. Therefore, it is recommended that the whole body of $A$. adenophora should be removed before starting pre-monsoon in Nepal. This could prevent the release of allelochemicals from invasive species and mix them into the soil. If the underground parts are left unremoved there will be new sprouts. The removed plant materials should be managed properly, for example, the burial of the removed parts could be one 
option of the management ${ }^{36}$. The alternate options might be the utilization of removal parts for composting as the application of compost from A. adenophora may be beneficial for some crop plants ${ }^{37}$.

We have tested $A$. adenophora uninvaded and invaded soils to know whether there is any change caused by invasions in the soil properties. It is well known that $A$. adenophora can bring changes in soil physicochemical parameters ${ }^{38}$. Impacts of $A$. adenophora on soil organic matters, soil nitrogen, soil phosphorus, and soil potassium may vary with seasons, exposure, and degrees invasion level and therefore, there is no unified rule on how A. adenophora alter soil parameters ${ }^{39}$. Hence, it is suggested that the influence of particular invasive species on the soil should be studied at different invaded locations.

Soil analysis shows differences in $\mathrm{pH}$, soil organic matter, total nitrogen, total phosphorus, and potassium (Table 2). A. adenophora had reduced the soil $\mathrm{pH}$. It could be one of the mechanisms to inhibit seed germination, seedling growth, and development of native species ${ }^{19}$. Soils may become acidic as a result of leaching allelochemicals through rainwater. Thapa et al. (2017) expected that the reduced $\mathrm{pH}$ in the A. adenophora may reduce the seedling growth and development of native Schima wallichii ${ }^{19}$. Here also, it is likely that the growth and development of native E. blanda and O. stellata might have affected by reduced pH. Nirola and Jha (2011) have found that the soil $\mathrm{pH}$ in the sites having high importance value index (IVI) of O. stellata was $5.60^{40}$ which is similar to our results. Previous studies regarding the soil $\mathrm{pH}$ for E. blanda are deficient.

The organic matter, total nitrogen, and available phosphorus in the A. adenophora invaded soil were high as compared to the uninvaded soil. The available potassium was also increased by the invasion of $A$. adenophora (Table 2). This result was contrasting with the finding of previous studies, for instance, Thapa et al. (2017) found that there were no significant changes in these parameters in Schima-Alnus forest in Nepal ${ }^{19}$. Soil samples in this study were taken from a mixed plant community of the uninvaded sites. Therefore, during comparison of these parameters, type of uninvaded sites should also be characterized. Moreover, the contradictory results on soil parameters may mislead the readers or researchers to understand the actual pattern of invasive species interactions. Hence, it is suggested that the plant community and history of alien plant invasion as well as the degree of invasion level should be considered to know the actual pattern of changes in soil properties by invasive plants. Also, updating the soil status of native plant communities on the periodic basis would have a great significance for future predictions.

From the results, it is obvious that increasing the content of organic matter, total nitrogen and phosphorus, and potassium in the invaded sites may support the native species. However, the allelopathic effects has an equal chance to harm the native species. It is necessary to evaluate the contribution of such nutrients by invasive plants and the other allelochemical dose released by them in the invaded sites. If the dose of harmful allelochemicals released is higher than the nutrient contribution to the soil, the native plants may not take benefits from the nutrients provided by invasive alien plants.

Based on the field observation, it was difficult to predict the reasons behind association between the native species (O. stellata and E. blanda) and invasive A. adenophora. Our results clarify that the duration of A. adenphora invasion is not much longer to replace these native species but it can be expected that if the process of inhibition due to allelochemicals washed by rainwater continues, these native species might be replaced in the future. The contribution of A. adenophora litter might be lesser than the contribution of fresh parts (leaves) because the litters (dry leaves) are seen only during the post-winter season and the amount is relatively less, while the fresh leaves sprout enormous from pre-monsoon that remain throughout the year. The current study highlights that the interaction between A. adenophora and native O. stellata and E. blanda is negative and based on the results it can be expected that the population of these native shrubs would be diminished gradually in the invaded sites. Hence, regular observation and abundance measurement of the native species are recommended to confirm our prediction.

In conclusion, the impacts of $A$. adenophora to E. blanda is negative because one component (litter) has an advantage whereas the two-components (root and fresh leaves) have inhibitory role. Regarding the native $O$. stellata, there is a stimulatory effect of $A$. adenophora on one part (aerial or underground) and an inhibitory effect on another part (aerial or underground). This effect may create abnormality in the root-shoot ratio. The results also show that the fresh leaves and root of $A$. adenophora are the parts which are the potential to produce harmful allelochemicals that can inhibit native species. The IR analysis confirmed four functional groups in the A. adenophora leachates that are $\mathrm{O}-\mathrm{H}$ Stretching (Hydroxyl), $\mathrm{N}-\mathrm{H}$ (Amines), $\mathrm{C}-\mathrm{H}$ stretching (Aromatic), and $\mathrm{C}-\mathrm{O}-\mathrm{C}$ stretching (Ethers). This result indicates that $A$. adenophora allelochemicals belong to these functional groups. Their concentrations may differ based on the vegetative parts of A. adenophora which may produce positive and negative effects on the growth and development of native species. Removal of the whole body of A. adenophora could prevent the release of allelochemicals from aerial and underground parts and mix them into the soil.

Soil analysis shows differences in $\mathrm{pH}$, soil organic matter, total nitrogen, total phosphorus, and potassium between $A$. adenophora invaded and uninvaded soils. Reduction in the soil $\mathrm{pH}$ by $A$. adenophora can be a mechanism to inhibit the native species. Comparing the concentrations of organic matter, total nitrogen, and total phosphorus in the invaded soil with previous findings, it is suggested that the plant community and history of alien invasion as well as the degree of invasion level should be considered to know the actual pattern of changes in soil properties by an alien invasion. Monitoring the soil status frequently in the invaded regions have great significance for the future predictions. Additionally, it is necessary to evaluate the positive contribution of nutrients and the negative effects of allelochemicals released from invasive plants to estimate the net effect on the growth and development of native species. 


\section{Materials and methods}

Test species. Two native shrubs Osbeckia stellata Buchanan-Hamilton ex Kew Gawler and Elsholtzia blanda (Benth.) Benth. were the native test species for the phytotoxicity of invasive A. adenophora. These species are found associated with $A$. adenophora in the invaded sites. E. blanda represents a member of the family Lamiaceae and O. stellata of the family Melastomataceae. Both reach a height up to $2 \mathrm{~m}$. E. blanda is an aromatic plant and yields essential oil. Both species are the highly valuable medicinal plants. E. blanda is used in cuts and wounds, cough, choleric diarrhoea, fever, hepatitis, nephritis, pharyngitis, and cardiovascular disorders ${ }^{41,42}$. O. stellata is used in the treatment of diarrhoea, dysentery, and juice of leaves is used for scabies treatment ${ }^{43}$. In addition, both the species are important elements of native species composition in subtropical regions of Nepalese forests.

Pot experiment. The native plants were grown in pots containing soil collected from the uninvaded area and treated with A. adenophora leachates and litter. Seeds of native E. blanda and O. stellata, and the soils were collected in February 2018 from the Takhtar Community Forest $\left(27^{\circ} 24^{\prime} 59.99^{\prime \prime} \mathrm{N}\right.$ and $85^{\circ} 01^{\prime} 60.00^{\prime \prime}$ E, elevation: 1750-1900 masl.). The community forest is located in Thaha Municipality -9, Chitlang village of Makawanpur district, Bagmati Province, Nepal. The average annual temperature in the Chitlang village area is $16.2{ }^{\circ} \mathrm{C}$ and the average annual rainfall is $2812 \mathrm{~mm}^{44}$. The seeds were brought to the Central Department of Botany, Tribhuvan University, Kirtipur, and stored at $4{ }^{\circ} \mathrm{C}$ in the airtight plastic bag until use.

Polyethylene pots (size $6 \times 10 \mathrm{~cm}^{2}$ ) were filled with $200 \mathrm{~g}$ of soil and the soil was moistened by $200 \mathrm{ml}$ distilled water. The seeds of native species were placed on moist filter paper at room temperature $\left(25 \pm 5^{\circ} \mathrm{C}\right)$ and allowed to germinate in dark. After the $7^{\text {th }}$ day of seed soaking, the seedlings grown were about 1 to $1.5 \mathrm{~cm}$ long. The seedlings of homogenous size were gently picked up and transplanted to the pots prepared. Six seedlings were transplanted to each pot containing the moist soil.

The native seedlings were grown in the pots with the following treatments (i) Control (distilled water), (ii) $A$. adenophora leachate (leachate obtained from $10 \mathrm{~g}$ leaves $/ 100 \mathrm{ml}$ distilled water), (iii) A. denophora root leachate (leachate obtained from $10 \mathrm{~g}$ root $/ 100 \mathrm{ml}$ distilled water), and (iv) A. adenophora litter ( $1 \mathrm{~cm}$ thick layer on pot surface). Each treatment had 6 replicated pots. Altogether there were 48 pots ( 4 treatments $\times 6$ replicates $\times 2$ native species $=48$ ).

The control pots were watered $(10 \mathrm{ml})$ using distilled water on an alternate day. Similarly, A. adenophora fresh leaf and root leachates were poured into the respective pots. The litter treatment pots were watered using $10 \mathrm{ml}$ distilled water over the litter. The pots were placed in the glasshouse of the Central Department of Botany, Tribhuvn University, Kathmandu, Nepal and allowed the seedlings to grow. The positions of the pots were randomly changed regularly in the glasshouse to minimize the positional effect. The temperature of the house ranged between 20 and $38{ }^{\circ} \mathrm{C}$ and moisture between 50 and $88 \%$. Plants were harvested on the $48^{\text {th }}$ days after seedling transplantation. After harvesting, the length and dry weight of roots and shoots were taken separately. The roots and shoots were dried in a hot air oven at $80^{\circ} \mathrm{C}$ for $24 \mathrm{~h}$ for the dry weight.

Infrared spectroscopy (IR) analysis. Infrared spectroscopy (IR) analysis of A. adenophora leaf, root, and litter leachates was done for determining the functional groups of chemicals present in the extract. A small quantity of each leachate was separately poured on the Attenuated Total Reflection (ATR) Diamond puck at ATR crystal of Fourier Transform Infrared Spectrometer (FTIR). The ATR is the method that allows the direct measurement of samples for FTIR. The IR spectrum was obtained using SHIMADZU IRPrestige-21, FTIR Spectrometer, Department of Plant Resource, Ministry of Forests and Environment, Government of Nepal, Thapathali, Kathmandu, Nepal. The samples were scanned 25 times with a resolution of 16 from $5000 \mathrm{~cm}^{-1}$ to $500 \mathrm{~cm}^{-1}$ wavenumber range. The spectrum of peaks with wavenumbers was recorded.

Soil analysis and chlorophyll estimation. Ageratina adenophora invaded and uninvaded soils were collected from Takhtar Community Forest, Chitlang, Makwanpur (surface soil from 5 to $15 \mathrm{~cm}$ ). Two-line transects were made, one along each invaded and uninvaded site in the forest. Ten plots of size $1 \mathrm{~m}^{2}$ were sampled at each transect. Altogether 20 soil samples were collected (10 from invaded and 10 from uninvaded plots). The uninvaded plots were free of $A$. adenophora whereas the cover of $A$. adenophora ${ }^{45}$ and the total nitrogen was estimated by the Kjeldahl method ${ }^{46}$. Estimation of phosphorus and potassium was followed by Olsen's bicarbonate method $^{47}$ and the Flame photometry ${ }^{48}$, respectively. Chlorophyll contents were estimated in the leaves sampled from the plants grown in pots under different treatments as mentioned in the pot experiment. Acetone (80\%) was used for extraction and the contents were measured using the method described by Bajracharya $(1999)^{49}$.

Statistical analyses. The growth parameters (root shoot length and dry weight) and chlorophyll content among different treatments (root leachate, leaf leachate and litter of $A$. adenophora) were compared using oneway ANOVA. Soil parameters ( $\mathrm{pH}, \mathrm{OM}$, total $\mathrm{N}$ and $\mathrm{K}$ ) between the A. adenophora invaded and uninvaded sites were compared using independent sample t-test but the phosphorus was compared using the Mann-Whitney $\mathrm{U}$ test as the data was not normal. The p-value $<0.05$ was considered statistically significant differences in the plant growth and soil parameters.

Ethics and research guideline statement. Research permission including the collection of plant materials was taken from the Department of Plant Resources (DPR), Ministry of Forests and Environment, Government of Nepal, Thapathali, Kathmandu, Nepal. The experiments were conducted following relevant guidelines and regulations. 
Received: 12 January 2021; Accepted: 14 June 2021

Published online: 01 July 2021

\section{References}

1. Cronk, Q. C. B. \& Fuller, J. L. Plant Invaders: The Threat to Natural Ecosystems (Chapman and Hall, 1995).

2. Tererai, F. \& Wood, A. R. On the present and potential distribution of Ageratina adenophora (Asteraceae) in South Africa. S. Afr. J. Bot. 95, 152-158 (2014).

3. Yu, F., Akin-Fajiye, M., Thapa Magar, K., Ren, J. \& Gurevitch, J. A global systematic review of ecological field studies on two major invasive plant species, Ageratina adenophora and Chromolaena odorata. Divers. Distrib. 22, 1174-1185 (2016).

4. Niu, H. B., Liu, W. X., Wan, F. H. \& Liu, B. An invasive aster (Ageratina adenophora) invades and dominates forest understories in China: Altered soil microbial communities facilitate the invader and inhibit natives. Plant Soil 294, 73-85 (2007).

5. Wang, J. J. Ageratina adenophora (Spreng.). In Biology and Management of Invasive Alien Species in Agriculture and Forestry (eds Wan, F. H. et al.) 651-661 (Science Press, 2005).

6. Yang, G., Gui, F., Liu, W. \& Wan, F. Crofton weed Ageratina adenophora (Sprengel). In Biological Invasions and Its Management in China (eds Wan, F. et al.) 111-129 (Springer, 2017).

7. Shrestha, B. B. Invasive alien plant species in Nepal. In Frontiers of Botany (eds Jha, P. K. et al.) 269-284 (Tribhuvan University, 2016).

8. Alka, C., Adhikari, B. S., Joshi, N. C. \& Rawat, G. S. Patterns of invasion by crofton weed (Ageratina adenophora) in Kailash sacred landscape region of western Himalaya (India). Environ. Conserv. J. 20, 9-17 (2019).

9. Balami, S. \& Thapa, L. B. Herbivory damage in native Alnus nepalensis and invasive Ageratina adenophora. Bot. Orient. 11, 7-11 (2017).

10. Thapa, L. B., Kaewchumnong, K., Sinkkonen, A. \& Sridith, K. Plant communities and Ageratina adenophora invasion in lower montane vegetation, central Nepal. Int. J. Ecol. Dev. 31, 35-49 (2016).

11. Thapa, L. B., Thapa, H. \& Magar, B. G. Perception, trends and impacts of climate change in Kailali District, Far West Nepal. Int. J. Environ. 4, 62-76 (2015)

12. Thapa, N. \& Maharjan, M. Invasive alien species: Threats and challenges for biodiversity conservation (A case study of Annapurna Conservation Area, Nepal). In Proc. International Conference on Invasive Alien Species Management, Chitwan, March 25-27, 2014 (eds Thapa, G. J. et al.) 18-22 (National Trust for Nature Conservation, 2014).

13. Tiwari, S., Adhikari, B., Siwakoti, M. \& Subedi, K. An Inventory and Assessment of Invasive Alien Plant Species of Nepal (IUCN Nepal, 2005)

14. Tripathi, R. S., Yadav, A. S. \& Kushwaha, S. P. S. Biology of Chromolaena odorata and Ageratina adenophora. In Invasive Alien Plants: An Ecological Appraisal for the Indian Subcontinent (eds Bhatt, J. R. et al.) 43-56 (CAB International Publishing, 2012).

15. Fu, D., Wu, X., Huang, N. \& Duan, C. Effects of the invasive herb Ageratina adenophora on understory plant communities and tree seedling growth in Pinus yunnanensis forests in Yunnan, China. J. For. Res. 23, 112-119 (2018).

16. Thapa, L. B., Kaewchumnong, K., Sinkkonen, A. \& Sridith, K. "Soaked in rainwater" effect of Ageratina adenophora on seedling growth and development of native tree species in Nepal. Flora 263, 151554 (2020).

17. Thapa, L. B., Kaewchumnong, K., Sinkkonen, A. \& Sridith, K. Airborne and belowground phytotoxicity of invasive Ageratina adenophora on native species in Nepal. Plant Ecol. 221, 883-892 (2020).

18. Wan, F. et al. Invasive mechanism and control strategy of Ageratina adenophora (Sprengel). Sci. China Life Sci. 53, 1291-1298 (2010).

19. Thapa, L. B., Kaewchumnong, K., Sinkkonen, A. \& Sridith, K. Plant invasiveness and target plant density: High densities of native Schima wallichii seedlings reduce negative effects of invasive Ageratina adenophora. Weed Res. 57, 72-80 (2017).

20. Wan, H., Liu, W. \& Wan, F. Allelopathic effect of Ageratina adenophora (Spreng.) leaf litter on four herbaceous plants in invaded regions. Chin. J. Eco-Agric. 19, 130-134 (2011).

21. Yang, G. Q., Wan, F. H., Guo, J. Y. \& Liu, W. X. Cellular and ultrastructural changes in the seedling roots of upland rice (Oryza sativa) under the stress of two allelochemicals from Ageratina adenophora. Weed Biol. Manage. 11, 152-159 (2011).

22. Zhang, F., Guo, J., Chen, F., Liu, W. \& Wan, F. Identification of volatile compounds released by leaves of the invasive plant croftonweed (Ageratina adenophora, Compositae), and their inhibition of rice seedling growth. Weed Sci. 60, 205-211 (2012).

23. Inderjit, E. H. et al. Volatile chemicals from leaf litter are associated with invasiveness of a Neotropical weed in Asia. Ecology $\mathbf{9 2}$, 316-324 (2011).

24. Yang, G. Q., Qiu, W. R., Jin, Y. N. \& Wan, F. H. Potential allelochemicals from root exudates of invasive Ageratina adenophora. Allelopathy J. 32, 233 (2013).

25. Zhu, X. Z., Guo, J., Shao, H. \& Yang, G. Q. Effects of allelochemicals from Ageratina adenophora (Spreng.) on its own autotoxicity. Allelopathy J. 34, 253 (2014).

26. Latif, S., Chiapusio, G. \& Weston, L. A. Allelopathy and the role of allelochemicals in plant defence. Adv. Bot. Res. 82, 19-54 (2017).

27. Siggia, S. Importance of functional group determination in organic quantitative analysis. J. Chem. Educ. 27(3), 141 (1950).

28. Rogers, E. R., Zalesny, R. S., Hallett, R. A., Headlee, W. L. \& Wiese, A. H. Relationships among root-shoot ratio, early growth, and health of hybrid poplar and willow clones grown in different landfill soils. Forests 10, 49 (2019).

29. Thornley, J. H. M. A balanced quantitative model for root: Shoot ratios in vegetative plants. Ann. Bot. 36, 431-441 (1972).

30. Mašková, T. \& Herben, T. Root: Shoot ratio in developing seedlings: How seedlings change their allocation in response to seed mass and ambient nutrient supply. Ecol. Evol. 8, 7143-7150 (2018).

31. Das, M. B. B., Acharya, B. D., Saquib, M. \& Chettri, M. K. Effect of aqueous extract and compost of invasive weed Ageratina adenophora on seed germination and seedling growth of some crops and weeds. J. Biodivers. Conserv. Bioresour. Manage. 4, 11-20 (2018).

32. Zhou, Z. Y. et al. Phenolics from Ageratina adenophora roots and their phytotoxic effects on Arabidopsis thaliana seed germination and seedling growth. J. Agric. Food Chem. 61, 11792-11799 (2013).

33. Zhang, M. et al. Bioactive quinic acid derivatives from Ageratina adenophora. Molecules 18, 14096-14104 (2013).

34. Dong, L. M. et al. Two new thymol derivatives from the roots of Ageratina adenophora. Molecules 22, 592 (2017).

35. Zhao, X. et al. Terpenes from Eupatorium adenophorum and their allelopathic effects on Arabidopsis seeds germination. J. Agric. Food Chem. 57, 478-482 (2009).

36. Kollmann, J., Brink-Jensen, K., Frandsen, S. I. \& Hansen, M. K. Uprooting and burial of invasive alien plants: A new tool in coastal restoration? Restor. Ecol. 19(3), 371-378 (2011)

37. Jiao, Y. et al. In situ aerobic composting eliminates the toxicity of Ageratina adenophora to maize and converts it into a plant-and soil-friendly organic fertilizer. J. Hazard. Mater. 410, 124554 (2021).

38. Chen, X. et al. (2015) Impacts of four invasive Asteraceae on soil physico-chemical properties and AM fungi community. Am. J. Plant Sci. 6, 2734 (2009).

39. Yu, F. K. et al. Impacts of Ageratina adenophora invasion on soil physical-chemical properties of Eucalyptus plantation and implications for constructing agro-forest ecosystem. Ecol. Eng. 64, 130-135 (2014).

40. Nirola, R. \& Jha, P. K. Phytodiversity and soil study of Shiwalik Hills of Ilam, Nepal: An ecological perspective. Ecoprint 18, 77-83 (2011). 
41. Lu, J. S., Shen, T., Guo, Z., Shen, X. W. \& Zheng, S. Z. The chemical constituents of Elsholtzia blanda. Acta Bot. Sin. 43, 545-550 (2001).

42. Singh, T. T., Sharma, H. M., Devi, A. R. \& Sharma, H. R. Plants used in the treatment of piles by the scheduled caste community of Andro village in Imphal East District, Manipur (India). J. Plant Sci. 2, 113-119 (2014).

43. Malla, B. \& Chhetri, R. B. Indigenous knowledge on medicinal non-timber forest products (NTFP) in Parbat district of Nepal. Indo. Glob. J. Pharm. Sci. 2, 213-225 (2012).

44. Climate-data.org. Chitlang Climate (Nepal) (2021). https://en.climate-data.org/asia/nepal/central-development-region/chitlang1061755/ (Accessed 2 April 2021).

45. Walkley, A. \& Black, I. A. An examination of the Degtjareff method for determining soil organic matter, and a proposed modification of the chromic acid titration method. Soil Sci. 37(1), 29-38 (1934).

46. Bremner, J. M. \& Mulvaney, C. S. Nitrogen-total. In Methods of Soil Analysis, Part 2 (eds Page, A. L. et al.) 595-624 (American Society of Agronomy, 1982).

47. Olsen, S. R., Cole, C. V., Watanable, F. S. \& Dean, L. A. Estimation of Available Phosphorus in Soils by Extraction with Sodium Bicarbonate. USDA Circular 939 (U.S. Govt Printing Office, 1954).

48. Toth, S. J. \& Prince, A. L. Estimation of cation-exchange capacity and exchangeable Ca, K, and Na contents of soils by flame photometer techniques. Soil Sci. 67(6), 439-446 (1949).

49. Bajracharya, D. Experiments in Plant Physiology. 51-52 (Narosa Publishing House, New Delhi, India, 1999).

\section{Acknowledgements}

This study was supported by University Grants Commission, Bhaktapur, Nepal (FRG-73/74-S\&T-01). We are grateful to the Department of Plant Resources (DPR), Ministry of Forests and Environment, Government of Nepal, Thapathali, Kathmandu, Nepal and Central Department of Environmental Science, Institute of Science and Technology, Tribhuvan University, Kirtipur, Kathmandu, Nepal for providing laboratory facilities. We are thankful to Prof. Emeritus Dr. Pramod Kumar Jha, Prof. Dr. Mohan Siwakoti, Prof. Dr. Rejina Maskey, and Prof. Dr. Ram Kailashi Prasad Yadav for every support during the study.

\section{Author contributions}

L.B.T. and R.R.P. designed the experiments and obtained funding. T.B.D., B.A., S.P., S.N. and K.B. performed the experiments, analyzed the data, and drafted the manuscript. T.D.B, G.P., and K.B.P. participated in data analysis and interpretations. All authors contributed to the revising of the manuscript.

\section{Competing interests}

The authors declare no competing interests.

\section{Additional information}

Correspondence and requests for materials should be addressed to L.B.T.

Reprints and permissions information is available at www.nature.com/reprints.

Publisher's note Springer Nature remains neutral with regard to jurisdictional claims in published maps and institutional affiliations.

(c) (i) Open Access This article is licensed under a Creative Commons Attribution 4.0 International License, which permits use, sharing, adaptation, distribution and reproduction in any medium or format, as long as you give appropriate credit to the original author(s) and the source, provide a link to the Creative Commons licence, and indicate if changes were made. The images or other third party material in this article are included in the article's Creative Commons licence, unless indicated otherwise in a credit line to the material. If material is not included in the article's Creative Commons licence and your intended use is not permitted by statutory regulation or exceeds the permitted use, you will need to obtain permission directly from the copyright holder. To view a copy of this licence, visit http://creativecommons.org/licenses/by/4.0/.

(C) The Author(s) 2021 